\title{
The Bologna Process and Its Impact on University-Level Chemical Education in Europe
}

\author{
Gabriel Pinto \\ Grupo de Innovación Educativa de Didáctica de la Química, ETS de Ingenieros Industriales, \\ Universidad Politécnica de Madrid, 28006 Madrid, Spain \\ gabriel.pinto@upm.es
}

The present reform of the European university system began in 1988, when university rectors met at Bologna University to celebrate its 900th anniversary. In a document known as Magna Charta Universitatum, they proposed a series of principles to guide policy makers and allow universities to remain centers of free thought and research, while better serving the cultural integrity and heritage of European societies. Ten years later, in May 1998, the ministers in charge of higher education of France, Germany, Italy, and the United Kingdom signed the Sorbonne Declaration (1) on the occasion of the 800th anniversary of this French university, encouraging the unification of the structure of the European higher education system in order to improve external recognition and student mobility as well as employability. With the Bologna Declaration ${ }^{1}$ of June 19, 1999, the number of signatory countries increased to 29 (many European Union member states and also nonmember states, such as Norway and Switzerland). The Bologna Declaration (2) is a pledge to reform the structures of the higher education systems of European countries, and it has a clearly defined common goal, which is the creation of a coherent European Higher Education Area (EHEA) based on international cooperation and academic exchange that is attractive to European students and staff as well as to students and staff from other parts of the world. The aim was to harmonize the different educational national systems by the year 2010 .

\section{The Bologna Process for European Higher Education Reform}

After signing the Bologna Declaration, the ministers in charge of higher education of the signatory countries met every 2 years in conferences in different cities (Prague, 2001; Berlin, 2003; Bergen, 2005; London, 2007; Leuven/Louvain-la-Neuve, 2009; and Budapest and Vienna, 2010) to follow up the process and to set directions and priorities for the coming years. These conferences were prepared by a Bologna follow-up group, which in turn receives input from working groups and Bologna seminars. The next ministerial meeting to take stock of progress will be hosted by Romania, in Bucharest, in April 2012.

As of September 2010, 47 countries are involved with the Bologna Process (3). A full list of participating countries and organizations can be found in Table 1 . The key principles of the Bologna Process, as defined in the Bologna Declaration and at the cited conferences are summarized in Table 2.

Diversity and variety on one side and cooperation and competition on the other will determine the construction of the EHEA. In other words, credits, examinations, and degrees must be convertible in the EHEA in the sense of "equivalent but not identical”. For example, degrees may be organized in a rich number of ways. The progress toward the gradual creation of this
European higher education space involves a process of structural change: it calls for the reform of national systems as well as for curricular and institutional change at universities and other institutions of higher education.

Among other aspects, the European Credit Transfer and Accumulation System (ECTS $)^{2}$ is established in the Bologna Process as a proper means of promoting widespread student mobility; this is explained below.

As is usually the case with structural reforms, the introduction and acceptance of the changes required are conditional, understanding the risks and opportunities, and can only be introduced on the basis of changed visions and attitudes. This is where the challenge is greatest. In fact, the Bologna or Convergence Process is not a bed of roses, and much skepticism and criticism has been voiced (4). For example, it is seen by some students and teachers as a neoliberal attempt to impose the logic of the market on European universities (5).

A number of academics have also criticized how the process is being implemented. For example, Veiga and Amaral pointed out that the implementation of the Bologna Process in Portugal has been achieved "in form" rather than "in substance". They observed inconsistencies, such as contradictions between the overall assessment of the process of adaptation and establishment of new degree programs, and the details associated with its implementation and difficulties in the curricular organization (6). In another example, with respect to chemistry educators in Sweden, Åkesson et al. recently formulated a critical question about the European convergence process (7): "did the universities and chemistry education make use of the opportunities for reform or did they stumble on the obstacles?"

Owing to the animated debate about the process in both governmental and educational circles, the Bologna Process has been advancing during the past decade and represents not only a starting point, but a source of inspiration for pending changes of university structures and pedagogical methodologies (8). In this context, in many European countries, legislative changes introduced after the adoption of the Bologna Declaration have contributed to an acceleration of the movement toward important reforms. In Spain, for example, the replacement of all old degrees by new ones has already started, the created accreditation council has been operational for the last 8 years (9), and the introduction of credit-based studies is reaching the operational phase at all universities. As an example of diversity, according to the Bologna Process, first-cycle studies should last a minimum of 3 years and be relevant to the European labor market; however, Spain has adopted the 4-year system (240 ECTS) despite the fact that most other participating countries have adopted a 3-year first cycle (180 ECTS), because students in Spain begin university studies 
Table 1. List of Countries and Organizations Participating in the Bologna Process

\begin{tabular}{|c|c|c|c|c|c|}
\hline \multicolumn{6}{|c|}{ Member Countries: } \\
\hline Albania & Croatia & Germany & Latvia & The Netherlands & Slovenia \\
\hline Andorra & Cyprus & Greece & Liechtenstein & Norway & Spain \\
\hline Armenia & Czech Republic & Holey See & Lithuania & Poland & Sweden \\
\hline Austria & Denmark & Hungary & Luxembourg & Portugal & Switzerland \\
\hline Azerbaijan & Estonia & Iceland & Malta & Romania & Turkey \\
\hline Belgium & Finland & Ireland & Moldova & Russian Federation & Ukraine \\
\hline Bosnia and & France & Italy & Montenegro & Serbia & United Kingdom \\
\hline Herzegovina & Georgia & Kazakhstan & Former Yugoslav & Slovak Republic & \\
\hline Bulgaria & & & Republic of Macedonia & & \\
\hline \multicolumn{6}{|c|}{ Additional Member: European Commission } \\
\hline \multicolumn{6}{|c|}{ Consultative Members: } \\
\hline \multicolumn{6}{|c|}{ European University Association (EUA) } \\
\hline \multicolumn{6}{|c|}{ European Association of Institutions in Higher Education (EURASHE) } \\
\hline \multicolumn{6}{|c|}{ European Students' Union (ESU) } \\
\hline \multicolumn{6}{|c|}{ Council of Europe } \\
\hline \multicolumn{6}{|c|}{ UNESCO European Centre for Higher Education (UNESCO-CEPES) } \\
\hline \multicolumn{6}{|c|}{ European Association for Quality Assurance in Higher Education (ENQA) } \\
\hline \multicolumn{6}{|c|}{ BUSINESSEUROPE } \\
\hline Education Inte & Pan-European & (El) & & & \\
\hline
\end{tabular}

Table 2. Main Action Lines of the Bologna Process

Place of Definition (Year)
$\begin{array}{ll}\text { Bologna Declaration } & \text { Actions Adopted } \\ \text { (1999) } & \text { 1. Adoption of a system of easily understandable, compatible, and comparable degrees } \\ \text { 2. Articulation of studies in a system essentially based on two main cycles (the undergraduate and postgraduate levels) } & \text { 3. Establishment of a common system of credits } \\ \text { 4. Promotion of mobility by the elimination of remaining obstacles to the transfer of students, teachers, researchers } \\ \text { and graduates }\end{array}$
$\begin{aligned} & \text { 5. Promotion of European cooperation in quality assurance and accreditation by developing comparable criteria } \\ & \text { and methodologies }\end{aligned}$
$\begin{aligned} & \text { 6. Promotion of the necessary European dimension in higher education through an organized follow-up and implementation } \\ & \text { structure that is based mainly on intergovernmental cooperation conducted in collaboration with education institutions }\end{aligned}$
$\begin{aligned} & \text { 7. Focus on lifelong learning that is essential to help meet the challenges of increased competition in the global workplace, } \\ & \text { and the use of new technologies }\end{aligned}$
$\begin{aligned} & \text { 8. Inclusion of higher education institutions and students as active partners } \\ & \text { 9. Promotion of the attractiveness of the European Higher Education Area }\end{aligned}$
$\begin{aligned} & \text { 10. Establishing the synergy between the European Higher Education Area and the European Research Area, } \\ & \text { as two pillars of a knowledge-based society }\end{aligned}$

${ }^{a}$ Focus has also extended beyond these two cycles so that doctoral level qualifications are now considered as the third cycle in the Bologna Process.

at the age of 18 (in other European countries students are one year older when beginning university) and because Spain has relationships with 4-year universities in Latin America and the United States.

\section{The European Credit Transfer and Accumulation System}

The definition of credits (systematic ways of describing educational programs by attaching units of value to their components) in higher education systems is based on different parameters, such as student workload, learning outcomes, and contact hours. It should be noted that the credit system was not used a few years ago in several countries in continental Europe, such as Spain.

The European Credit Transfer and Accumulation System (ECTS) is a student-centered system (10) based on the student workload required to achieve the objectives of a program, specified in terms of the learning outcomes and competencies to be acquired. It was introduced in 1989, before the Bologna Declaration, within the framework of the Erasmus program. ${ }^{3}$ In short, the key features of ECTS are summarized below:

- It is based on the principle that 60 credits measure the workload of a full-time student during one academic year. The student workload of a full-time study program in Europe amounts to around $1500-1800 \mathrm{~h}$ per year, and one credit stands for around 25-30 working hours. At this point, it is pertinent to note the comparison to the U.S. 9-month academic year, in which a fulltime load is considered 32 credits, with each credit representing $15 \mathrm{~h}$ of in-class instruction (more, with a laboratory course) or 
about 480 total hours of in-class instruction. It is often said in the U.S. that students should study, outside of class, $3 \mathrm{~h}$ for each hour of in-class instruction, which totals a study time of $1440 \mathrm{~h}$ in addition to the 480 in-class hours. This seems comparable to the ECTS model.

- Credits can only be obtained after successful completion of the work required and appropriate assessment of the learning outcomes achieved.

- Student workload in ECTS consists of the time required to complete all planned learning activities, such as attending lectures and seminars, independent and private study, preparation of projects, examinations, and so forth.

- Credits are allocated to all educational components of a study program (such as modules, courses, placements, dissertation work, etc.) and reflect the quantity of work each component requires to achieve its competencies (specific objectives or learning outcomes) in relation to the total quantity of work necessary to complete a full year of study successfully.

- The performance of the student is documented by a local or national grade. The ECTS grading scale ranks the students on a statistical basis. Grades are assigned among successful students as follows: $\mathrm{A}=$ top $10 \%, \mathrm{~B}=$ next $25 \%, \mathrm{C}=$ next $30 \%, \mathrm{D}=$ next $25 \%$, and $\mathrm{E}=$ bottom $10 \%$. A distinction is made between the grades FX and F that are used for unsuccessful students. FX means that the student failed and some more work is required before the credit can be awarded, and F means that the student failed considerable amounts of the work and that considerable further work is required. As an approach to the analysis of the equivalences between ECTS grading scale and U.S. grades, reading the paper by Haug is recommended (11).

ECTS intends to make study programs easy to read and comparable for all students (local and foreign), facilitates mobility and academic recognition, and helps universities to organize and to revise their study programs. Still, ECTS is not simply related to student workload. It has enormous potential for reforming and improving higher education curricula, cultures of learning, and structures if its introduction includes an integrative format with these essential components: student workload, competencies and standards, learning outcomes, ways of documenting the preceding components, and a flexible system of interinstitutional recognition of the accumulation of credits earned by students in various education settings (e.g., virtual learning environments).

The meaningful implementation of this kind of credit system implies that it is possible to successfully complete study programs within a specific time frame defined by the workload of students, an enormous reorientation for a number of European university programs. Coherent introduction of ECTS implies far-reaching changes in the professional responsibilities and working contracts of higher education staff, as well as changes of learning cultures, with students as autonomous learners responsible for their own learning processes.

\section{Innovation in European University Chemistry Education}

As noted previously, criticism of the Bologna Process has emerged. However, for a number of university chemistry educators, the Bologna Process is seen as an opportunity for positive change in teaching and learning methods. Although some changes have been introduced in past years to university chemistry courses, the main method of teaching (excepting laboratory courses) in countries such as Spain was, until recently, the lecture. Students did not spend much time studying independently; rather they spent their time listening to lectures and taking notes, and tutorials were seldom offered. Outside of attending lectures, students were only required to complete assignments and, at the end of the semester, to pass the final examination. The situation was not very different from that described in this Journal almost 50 years ago, under the title of "Chemical Education in Spain" (12). But this situation is changing, fortunately, owing primarily to the Bologna Process.

A critical aspect of the ECTS is helping students to become more active learners. In this context, it is necessary to significantly reform the structure and instructional style of chemistry courses. Active-learning techniques include cooperative learning, handson activities, real-world applications, and engaging technology. Several meaningful strategies include the use of problem-based learning (by means of challenging tasks for students), case studies, interdisciplinary approaches, team participation, concept mapping, and online learning $(13,14)$.

A large-scale, university-run project called Tuning Educational Structures in Europe, ${ }^{4}$ usually known as the Tuning Project, has been trying to find the necessary tools for implementation of the Bologna Process (15). This initiative started in 2000 as a project to link the political objectives of the Bologna process to the university. Over time, the Tuning Project has developed into an approach to implement, evaluate, and enhance quality education for first-, second-, and third-cycle degree programs. The Tuning Project outcomes as well as its tools are presented in a variety of free publications (15), such as Reference Points for the Design and Delivery of Degree Programs in Chemistry, which institutions and their academics are invited to test and use. The Tuning Project focuses not on educational systems, but on educational structures with an emphasis on the subject area level (i.e., the content of studies).

The introduction of a two or three cycle system (undergraduate and postgraduate) according with the Bologna Process makes it necessary to revise present study programs in several European countries, which are not based on the concept of cycles. And it must be taken into account that the first two cycles should give access not only to the following cycle, but also to the labor market. This shows the relevance of using the concept of competencies as a basis for learning outcomes that constitutes an important focus for educative innovation.

The Tuning Project distinguishes between learning outcomes and competencies in order to consider the different roles of the most relevant players: academic instructors and learners. Learning outcomes are considered as statements of what a learner is expected to know, understand, or be able to demonstrate after completion of learning. These learning outcomes can refer to a single course unit or to a period of studies. Learning outcomes specify the requirements for awarding credit.

On the other hand, competencies are obtained or developed during the process of learning by the student, and they represent a dynamic combination of knowledge, understanding, skills, and abilities. In this context, fostering competencies is the object of educational programs, and these competencies will be formed in various course units and assessed at different stages.

According to the Tuning Project, competencies can be distinguished in subject-specific and generic or transferable ones. Developing subject-specific knowledge and skills for university 
degree programs is of great interest, but the Tuning Project highlights the fact that attention should also be devoted to the development of generic competencies, because they are becoming more and more relevant for preparing students well for their future role in society in terms of employability and citizenship.

This Tuning Project distinguishes three types of generic competencies: instrumental competencies (cognitive abilities, methodological abilities, technological abilities, and linguistic abilities); interpersonal competencies (individual abilities such as social skills, social interaction, and cooperation); and systemic competencies (abilities and skills concerning whole systems, such as combination of understanding, sensibility, and knowledge), in which prior acquisition of instrumental and interpersonal competencies is prerequisite.

As a part of the Tuning Project, a large-scale consultation was organized among graduates, employers, and academics to identify the most important generic competencies for each of the academic fields. In all fields, the most important identified competencies included the capacity for analysis and synthesis and the capacity to learn to solve problems, but other generic competencies were seen as being very important for employability, such as: the capacity to apply knowledge to practice; the capacity to adopt to new situations; concern for quality; information management skills; the ability to work autonomously; team work; oral and written communication in the native language; and the capacity to organize and plan. Subject-specific competencies have been also identified for several subject areas, including chemistry. It must be noted that the competencies from the Tuning Project are described as reference points for curriculum design and evaluation, not as obligations, because they allow flexibility and autonomy. For example, the use of learning outcomes allows greater flexibility than more traditionally designed study programs, because they show that different pathways can lead to comparable outcomes.

More information about the extended consultation process achieved by the Tuning Project can be found on its Web site (15). From a different starting point, interesting comments about how to teach and to assess several generic competencies were published recently by Felder (16).

\section{The Chemistry Eurobachelor: A European Standard Bachelor Program in Chemistry}

As Mitchell pointed out recently, to those looking in from the outside, university chemistry education in "old Europe" seemed slightly incomprehensible $(17,18)$. The United Kingdom and Ireland had Bachelor's Degree and Master's Degree programs, but continental Europe was characterized by a great variety of first degrees (called, for example, Licenciatura, Laurea, Candidatus, Licencié, Maitre, and Diplom), which did not seem to fit in well with what other countries were offering. All this, however, started to change in the past few years owing to the Bologna Process, because this process is driving higher education reform in Europe, bringing the European system closer to that of the United States and the United Kingdom. In particular, it has introduced a BachelorMasters-Ph.D. system, and this is a radical move in many European countries, such as Spain. For example, in Spain before the Bologna Process, university chemistry education was organized in a Licenciatura (usually of 5 years of study but sometimes 4 years, depending on the university) and a Ph.D. (usually around 4 years).
The European Chemistry Thematic Network (ECTN), a group representing over 120 universities and national chemical societies, has devised a framework for a 180-credit (3-year) bachelor's degree program in chemistry, called the Chemistry Eurobachelor, which is intended to set a standard for chemistry higher education in Europe (19). The degree is designed to have consistent learning outcomes, skills, and competencies. The primary aim of the Eurobachelor qualification is to provide a standard first-cycle degree recognized by European institutions as having sufficient quality to provide automatic right of access to chemistry Master's degree programs. The goals of a first-cycle study program were based on the descriptors developed by the Chemistry Subject Area Group working in the Tuning Project, as summarized in Table 3.

As shown in Table 3, students at the Eurobachelor level are expected to develop a wide range of different abilities, skills, and competencies that may be divided into three broad categories. Apart from the bachelors thesis (an individual research or industrial project, the results of which will be presented in the form of a written report), which will be the last module in the course to be completed, modules are: compulsory (and will deal with the main subdisciplines of analytical chemistry, inorganic chemistry, organic chemistry, physical chemistry, and biological chemistry), semioptional (with study in at least three additional chemistry-related subdisciplines, such as computational chemistry, chemical technology, macromolecular chemistry, and biochemistry), and elective. Practical courses may be organized as separate modules or as integrated modules, but they must continue to play an important role in university chemical education in spite of financial constraints imposed by the situation of individual institutions.

Modules corresponding to a total of at least 150 credits (including the bachelor's thesis) should deal with chemistry, physics, biology, or mathematics. Each individual institution will make its own decision as to the distribution of credits between compulsory, semioptional, and elective modules. It will, however, be necessary to define a core (with a volume of $50 \%$ of the total number of credits, i.e., 90 out of 180) in the form of a recommended minimum number of credits for the main subdisciplines, mathematics, and physics. Language modules will often be semioptional, as the Eurobachelor should be proficient in a second major European language (these being English, German, Italian, French, and Spanish) as well as his or her native language.

The academic goal of the bachelor degree in the chemical sciences is to give graduates an initial research experience. The intention is that the graduate will successfully complete an individual research project. Thus, the bachelor's thesis should normally carry at least 15 credits of research. An industrial placement may be considered a valid alternative to a bachelor's thesis. In addition, projects leading to the bachelors' thesis could well involve teamwork, as this is an important aspect of employability that is often neglected in traditional chemistry degree curricula.

Lectures should be supported by multimedia teaching techniques wherever possible and also by problem-solving classes. Institutions are advised to consider the introduction of tutorial systems. To avoid overloading the students, it is important that there is regular contact between the teachers of the modules.

Following the successful introduction of the Eurobachelor label, the ECTN has developed a framework for a second-cycle qualification in chemistry, known as Euromaster (19). The primary aims of the Euromaster qualification are to provide a second-cycle 
Table 3. Characteristics of First-Cycle Degrees in Chemistry, in Accordance with the Eurobachelor ${ }^{a}$

Kind of Abilities and Competencies

Chemistry-related cognitive abilities and competencies

Chemistry-related practical skills

Generic competencies that may be developed in the context of chemistry and are of a general nature applicable in many other contexts

\section{Competencies To Be Acquired by Students}

To have a good grounding in the core areas of chemistry (inorganic, organic, physical, biological, and analytical chemistry) and, in addition, the necessary background in mathematics and physics.

To have basic knowledge in several other more specialized areas of chemistry (such as computational chemistry, materials chemistry, macromolecular chemistry, biochemistry, or radiochemistry).

Regarding specific content, all programs should ensure that students become conversant with these main aspects of chemistry:

Chemical terminology, nomenclature, conventions, and units

The major types of chemical reactions and the main characteristics associated with them

The principles and procedures used in chemical analysis and the characterization of chemical compounds

The principal techniques of structural investigations, including spectroscopy

The characteristics of the different states of matter and the theories used to describe them

The principles of quantum mechanics and their application to the description of the structure and properties of atoms and molecules

The principles of thermodynamics and their applications to chemistry

The kinetics of chemical change, including catalysis; the mechanistic interpretation of chemical reactions

The characteristic properties of elements and their compounds, including group relationships and trends within the periodic table

The structural features of chemical elements and their compounds, including stereochemistry

The properties of aliphatic, aromatic, heterocyclic, and organometallic compounds

The nature and behavior of functional groups in organic molecules

Major synthetic pathways in organic chemistry, involving functional group interconversions and carbon-carbon and carbon-heteroatom bond formation

The relationship between bulk properties and the properties of individual atoms and molecules, including macromolecules (both natural and human-made), polymers, and other related materials

The structure and reactivity of important classes of biomolecules and the chemistry of important biological processes

To have built up practical skills in chemistry (in the safe handling of chemical materials and in the use of instrumentation in synthetic and analytical work) during laboratory courses, at least in inorganic, organic, and physical chemistry, in which they have worked individually or in groups as appropriate to the area.

To have developed generic skills in the context of chemistry that are applicable in many other contexts.

To have attained a standard of knowledge and competence that will give them access to second-cycle course units or degree programs.

To have the ability to gather and interpret relevant scientific data and make judgments that include reflection about relevant scientific and ethical issues.

To have the ability to communicate information, ideas, problems, and solutions to informed audiences

To have competencies that prepare them for entry-level graduate employment in the general workplace, including the chemical industry.

To have developed those learning skills that are necessary for them to undertake further study with a sufficient degree of autonomy.

${ }^{a}$ For more information, see ref 19 .

degree of the highest standard that will be recognized by European institutions as being of a standard that will provide automatic right of access (though not right of admission, which is the prerogative of the receiving institution) to chemistry doctoral programs, and recognized by employers as being of a standard that prepares the graduates for employment as professional chemists in chemical and related industries or in public service.
The second-cycle study program goals are summarized in Table 4. Chemistry degree programs offered by individual institutions will thus logically have their own particular characteristics, but any master's degree program must end with a thesis, as this will generally be considered to be the necessary prerequisite for access to the third cycle under the Bologna Process. 
Table 4. Characteristics of Second-Cycle Degrees in Chemistry, in Accordance with the Euromaster ${ }^{a}$

\begin{tabular}{|c|c|}
\hline Kind of Abilities and Competencies & Competencies To Be Acquired by Students \\
\hline $\begin{array}{l}\text { Chemistry-related cognitive abilities } \\
\text { and competencies }\end{array}$ & $\begin{array}{l}\text { To have knowledge and understanding that is founded upon and extends that of the bachelor's } \\
\text { level in chemistry, and that provides a basis for originality in developing and applying ideas } \\
\text { within a research context. }\end{array}$ \\
\hline Chemistry-related practical skills & $\begin{array}{l}\text { To have competencies that fit them for employment as professional chemists in chemical and } \\
\text { related industries or in public service. }\end{array}$ \\
\hline $\begin{array}{l}\text { Generic competencies that may be developed } \\
\text { in the context of chemistry and are of a } \\
\text { general nature applicable in } \\
\text { many other contexts }\end{array}$ & $\begin{array}{l}\text { To have attained a standard of knowledge and competency that will give them access } \\
\text { to third-cycle course units or degree programs. } \\
\text { To have the ability to apply their knowledge, understanding, and problem-solving abilities to } \\
\text { new or unfamiliar environments within broader (or multidisciplinary) contexts related } \\
\text { to chemical sciences. } \\
\text { To have the ability to integrate knowledge, handle complexity, and formulate judgments with } \\
\text { incomplete or limited information, including reflecting about ethical responsibilities linked } \\
\text { to the application of their knowledge and judgments. } \\
\text { To have the ability to communicate their conclusions, and the knowledge and rationale } \\
\text { underpinning these, to specialist and nonspecialist audiences clearly and unambiguously. } \\
\text { To have developed those learning skills that will allow them to continue to study in a manner } \\
\text { that may be largely self-directed or autonomous, and to take responsibility for their own } \\
\text { professional development. }\end{array}$ \\
\hline
\end{tabular}

${ }^{a}$ For more information, see ref 19.

\section{Summary}

To make European education the pinnacle of academic excellence, ministers, policy-makers, and European educators have taken the initiative to reform the university system using the tools of the so-called Bologna Process. The common tools in the emerging EHEA, such as the ECTS credits (a studentcentered system based on the student workload required to achieve the objectives of a program, specified in terms of the learning outcomes and competencies to be acquired), diploma supplement, a three-cycle system (composed of bachelor's, master's, and doctoral degrees), and qualification frameworks, all aim to provide an equivalent (but not identical) and harmonized system that is easy to understand for institutions, students, and employers. The project is a continent-wide effort that will consequently take decades to reach full adoption. For readers interested in the implementation and the impact of the process in a country such as Spain, the Web site developed by the Spanish Department of Education is a suggested source (20).

The overall goal is to establish a European higher education area by 2010 that will allow students to move freely between European countries without having to translate their credits or qualifications. The proposed system of credits promotes a shift from teaching to learning in university education.

Concerning chemistry education, several aspects that are being considered within the Bologna Process include: adoption of modern pedagogical methodologies; consideration of specific, generic, and transferable competencies as a basis for learning outcomes; and a framework bachelor's degree program in chemistry called the European Eurobachelor, which is intended to set a standard for chemistry higher education.

\section{Acknowledgment}

The author gratefully recognizes the support provided by the Universidad Politécnica de Madrid under Project IE09053505. The author is also grateful to Paul Kelter and to reviewers for valuable comments on the manuscript.

\section{Notes}

1. The Bologna Process is named after the place where it was proposed, the University of Bologna, in Bologna, Italy, which is considered one of the oldest continually operating degreegranting universities in the world.

2. The acronym ECTS made reference to the European Credit Transfer System because it was set up initially for credit transfer; it facilitated the recognition of periods of study abroad and thus enhanced the quality and volume of student mobility in Europe. Later, the term "and accumulation" was added to denote that it also is a system for accumulation of credits, but the original acronym remains.

3. The European Community action scheme for the mobility of university students (Erasmus Program) was established in 1987. It is named after the philosopher, theologian, and humanist, Erasmus of Rotterdam (1465-1536). An untiring adversary of dogmatic thought in all fields of human endeavor, Erasmus lived and worked in several parts of Europe in quest of the knowledge, experience, and insights that only such contacts with other countries and cultures could bring. By leaving his fortune to the University of Basel, he became a precursor of mobility grants.

4. The word "tuning" was chosen for the process in order to reflect the idea that universities do not and should not look for uniformity in their degree programs or any sort of unified, prescriptive, or definitive European curricula, but simply look for points of reference, convergence, and common understanding.

\section{Literature Cited}

1. The Sorbonne Joint Declaration. http://www.bologna-berlin2003.de/ pdf/Sorbonne_declaration.pdf (accessed on Aug 2010).

2. The Bologna Declaration of 19 June 1999. http://www.magna-charta. org/pdf/BOLOGNA_DECLARATION.pdf (accessed on Aug 2010).

3. Bologna Process: Participant Countries and Organizations. http:// www.ond.vlaanderen.be/hogeronderwijs/bologna/pcao/ (accessed on Aug 2010).

4. Caddick, S. EMBO Rep. 2008, 9 (1), 18-21.

5. Lorentz, C. F. G. Sociologia Int. 2006, 44, 123-151. 
6. Veiga, A.; Amaral, A. High. Educ. 2009, 57, 57-69.

7. Åkesson, E.; Elmgren, M.; Edstrom, K. Chem. Int. 2008, 30 (4), 13-15. http://www.iupac.org/publications/ci/2008/3004/3_akesson. html (accessed on Aug 2010).

8. Official Web Site of the Bologna Process. http://www.ond.vlaanderen. be/hogeronderwijs/bologna/ (accessed on Aug 2010).

9. Agencia Nacional de Evaluación de la Calidad y Acreditación. http://www.aneca.es/en.aspx (accessed on Aug 2010).

10. European Commission, Education and Training, European Credit Transfer and Accumulation System. http://ec.europa.eu/ education/lifelong-learning-policy/doc48_en.htm (accessed on Aug 2010).

11. Haug, G. World Education News \& Reviews 1997, 10 (2). http:// www.wes.org/gradeconversionguide/articlewindow.htm (accessed on Aug 2010).

12. Anderson, K. P. J. Chem. Educ. 1962, 39, 316-318.
13. Pinto, G. Chem. Educ. 2005, 10, 317-319.

14. Pinto, G.; Gauthier, C. V.; Weaver, G.; Kelter, P. B. Chem. Educ. 2008, 13, 186-189.

15. Tuning Educational Structures. http://unideusto.org/tuning/ (accessed on Aug 2010).

16. Felder, R. Chem. Eng. Educ. 2010, 44 (1), 63-65.

17. Mitchell, T. Chem. Int. 2004, 26 (5). http://www.iupac.org/publications/ci/2004/2605/3_mitchell.html (accessed on Aug 2010).

18. Mitchell, T. Chem. Int. 2007, 29 (4). http://www.iupac.org/publications/ci/2007/2904/3_mitchell.html (accessed on Aug 2010).

19. The Chemistry Quality Eurolabels Official Web Site. http:// ectn-assoc.cpe.fr/chemistry-eurolabels/ (accessed on Aug 2010).

20. Gobierno de España. Ministerio de Educación. What Is the University of Bologna Plan Like? http://www.queesbolonia.es/en/queesbolonia/ inicio.html (accessed on Aug 2010). 